BACKGROUND: Endometriosis, uncontrolled proliferation of ectopic and eutopic endometriotic tissues, is common in women at reproductive age, and may affect fertility. The role of macrophages in the pathogenesis is well proved, but engagement of $T$ cells in the pathogenesis of endometriosis is a matter of controversy

Aims: T-cell involvement in the pathogenesis of endometriosis was the objective of our study performed on women aged 24-46 years with diagnosed endometriosis. All the patients that were studied underwent diagnostic laparoscopy.

Methods: We evaluated the distribution of T-lymphocyte subpopulations in peripheral blood ( $\mathrm{PB})$, peritoneal fluid (PF) and in endometriotic tissues (ET), as well as cytokines [interleukin (IL)-2, IL-4, IL-10, IL-12, interferon (IFN)- $\gamma$ ] production by peripheral blood lymphocytes. IFN- $\gamma$, tumor necrosis factor (TNF)- $\alpha$, IL4 and IL-6 were investigated for their intracellular presence. The experiments were carried out before and after 6 months treatment with the GnRHAnalogous Goserelin (Zeneca Pharmaceuticals). The number of performed investigations is presented. Statistical analysis was performed using Statistica/ Win 5.0 software and Student's $t$-test, the paired Student $t$-test and Fisher's exact test when appropriate.

Results: We have compared the lymphocyte subset re-distribution with regard to the American Fertility Society (AFS) stages and scores, but no differences were observed. The significant increase in $\mathrm{CD} 4: \mathrm{CD8}$ ratio, the decrease in the number of natural killer (NK) cells in PB and the decrease in CD4:CD8 ratio in PF and ET of women with endometriosis was noted. The diminished IFN- $\gamma$ secretion by phytohemagglutinim (PHA)-stimulated lymphocytes in vitro derived from women with endometriosis and increased IL-4 production may be responsible for defective immunosurveillance against overgrowth of endometriotic tissues. The diminished NK cells number in PB of women with endometriosis argues for such a hypothesis. The increased deposits of proinflammatory IL-6 and TNF- $\alpha$ in the $T$ lymphocytes of women with endometriosis may be related to $T$-regulatory lymphocyte function and their inability to suppress cell proliferation in endometriosis. GnRH-Analogous Goserelin treatment normalises cytokine production and induces patient recovery.

Conclusions: The significant functional and phenotypic differences between the lymphocytes from healthy women and women with endometriosis were noted. The diminished IFN- $\gamma$ production in relation to decreased NK cells number and the increased IL-4 production before the treatment and normalisation after the treatment suggest the involvement of the deregulated T-cell system in the growth stimulation and recruitment of endometriotic cells. The increased CD4:CD8 ratio, IL-6, TNF- $\alpha$ deposits and diminished anti-inflammatory IL-10 production by lymphocytes may participate in the pathogenesis of endometriosis, and may secondarily affect the monocyte/macrophage function.

Key words: Endometriosis, T-regulatory cells, Diminished IFN- $\gamma$ production, NK cells, Increased IL- 4 production

\section{The involvement of $T$ lymphocytes in the pathogenesis of endometriotic tissues overgrowth in women with endometriosis}

\author{
Krzysztof Szyllo', Henryk Tchorzewski ${ }^{2,3, C A}$, \\ Malgorzata Banasik ${ }^{2}$, Ewa Glowacka², \\ Przemyslaw Lewkowicz ${ }^{2}$ and Anna Kamer- \\ Bartosinska ${ }^{1}$
}

${ }^{1}$ Surgical Gynecology Department and ${ }^{2}$ Department of Clinical Immunology, Research Institute of Polish Mother's Memorial Hospital, Rzgowska Str. 281/289, 93-338 Lodz, Poland; ${ }^{3}$ Pathophysiology and Immunology Department, Medical University, Lodz, Poland

\footnotetext{
${ }^{\mathrm{CA}}$ Corresponding author

Tel: +48422711264

Fax: +48422711

E-mail: htchorzewski@kki.pl
} 


\section{Introduction}

Ectopic growth of human endometrial cells is a common gynecological pathology associated with high recurrence rate and infertility. The precise mechanism of proliferation of endometrial cells is not clearly understood. Autocrine regulation of cell growth is proposed as a key factor of implantation and proliferation in endometriosis. RANTES (regulated on activation ectopic normal $\mathrm{T}$ cells expressed and secreted) mRNA chemokine expression was demonstrated in the normal endometrium and endometriotic implants stimulated with proinflammatory cytokines. ${ }^{1}$ Chemokine-activated regulatory CD4 cells suppress the proliferation and function of CD8 cells, which are particularly good interferon (IFN)- $\gamma$ producers. ${ }^{2}$ Proinflammatory chemokine production in turn stimulates the entry of macrophages into the endometriotic tissue. ${ }^{1}$ Proinflammatory cytokines such as tumor necrosis factor (TNF)- $\alpha$, interleukin (IL)-1, IL-4 and IFN- $\gamma$ induce RANTES production by cultured human endometrium. ${ }^{3}$ IFN- $\gamma$ synergistically enhances the TNF- $\alpha$-induced RANTES expression, which is inhibited by IL-4. IL-12 induces proliferation and cytotoxicity of $\mathrm{T}$ cells and natural killer (NK) cells. IL-12 was not detected in human peritoneal fluid of women with and without endometriosis or in the supernatants of endometrial cell cultures. ${ }^{4}$ PHAstimulated production of IL-12 by respective cells has not been analysed until now.

The T-cell subset re-distribution depends on chemokine and cytokine autocrine function, and probably does not correlates with endometriosis clinical symptoms. The contribution of IL-4 secreting $\mathrm{T}$ helper type (Th) 2 cells and diminished immunoregulatory IFN- $\gamma$ production together with decreased NK cells number may take part in the pathogenesis of endometriosis. The data in the present paper support the hypothesis that defective T-cell and NK-cell immunosurveillance against ectopic or eutopic overgrowth of endometriotic tissues is involved in the pathogenesis of this disease.

\section{Materials and methods}

\section{Subjects}

The investigations of T-lymphocyte subset re-distribution were performed on 60 women aged between 24 and 46 years who complained of pelvic pain, dysmenorrhea and infertility. None of the patients that were studied had received any hormonal treatment in the previous 3 months. Endometriosis was diagnosed in women undergoing diagnostic laparoscopy, which was performed in the follicular phase of the menstrual cycle and classified according to the revised American Fertility Society classification. ${ }^{5}$
During the laparoscopy, women with endometriotic cysts had the cysts opened and drained. Material from the cyst walls was submitted for histopathological and immunological investigations. Punch biopsy specimens from peritoneal lesions $(2-3 \mathrm{~mm}$ and more in diameter) were submitted to similar investigations. Peritoneal fluid was aspired from the Douglas pouch of women with endometriosis into sterile heparinised tubes immediately after insertion of the trocar, and transferred to the laboratory and processed within 30-45 min. Samples of the peripheral blood and aspirates from the peritoneal cavity were submitted to cytometric analysis using the Becton Dickinson Simulset ${ }^{\mathrm{TM}}$ (Becton Dickinson, San Jose, CA, USA) IMK-Lymphocyte reagent kit for enumerating $\mathrm{T}$ lymphocytes (CD3, CD4, CD8, CD4:CD8 ratio) and B lymphocytes (CD19). After laparoscopic confirmation of endometriosis, women were submitted to treatment with GnRH-Analogous Goserelin (Zeneca Pharmaceuticals) for 6 months. The diagnostic laparoscopy was repeated in those patients only who accepted the proposition. Peripheral blood samples were taken from the study group for the purpose of assessing T-cell subpopulations and cytokine production by these lymphocytes. Endometriotic tissues from the chocolate cyst walls or the material from the peritoneal lesions were mechanically disrupted using Medimachine (Consul 15) equipped with 50 $\mu \mathrm{m}$ filters. Single cell suspensions $2 \times 10^{6}$ were washed twice with phosphate-buffered saline, and submitted to Simulset IMK-Lymphocyte reagent labeling and cytometric analysis of lymphocyte subsets. The dead cell contamination was evaluated using the Trypan Blue exclusion method and never exceeded 3-4\%. Thirty women without any evidence of endometriosis who underwent laparoscopic investigation because of infertility, chronic pelvic pain, or functional cysts of the ovary served as the control group.

The whole study was performed with the permission of the Institute Ethics Committee.

\section{Cytokine evaluation}

Lymphocytes were isolated on a Gradisol gradient, washed and cultured $\left(1 \times 10^{6} / \mathrm{ml}\right)$ in a $\mathrm{CO}_{2}$ incubator in 0.2 Nunc plates in RPMI medium supplemented with $10 \%$ fetal calf serum (Hungarpol), glutamine, and antibiotics. PHA $(5 \mu \mathrm{g} / \mathrm{ml}$; Sigma $)$ was used as a stimulant and, after $72 \mathrm{~h}$ culture $\left(1 \times 10^{6}\right.$ cells $\left./ \mathrm{ml}\right)$, the cultures were terminated and the supernatants stored at $-72^{\circ} \mathrm{C}$ for IL evaluation. Due to technical reasons (resignations, refusal of blood collection, not completed treatment) some were excluded; consequently, cytokine evaluations were performed in randomly chosen patients. Measurements of IFN- $\gamma$, IL-2, IL-4, IL-10 and IL-12 cytokines production were performed using enzyme-linked 
immunosorbent assay Endogen kits according to the manufacturer's instructions. Intracellular staining (ICS) of the whole blood cells for the intracellular presence of IFN- $\gamma$, TNF- $\alpha$, IL- 4 and IL- 6 molecules was performed according to the producer's instruction. One milliliter of whole blood was diluted 1:1 with RPMI; diluted blood sample cells were stimulated with Phorbol Myristate Acetate (PMA) (Sigma, Saint Louis, MO, USA) $(50 \mu \mathrm{g} / \mathrm{ml})$ or ionomycin (100 $\mu \mathrm{M}$ final concentration) in the presence of brefeldin (protein transport inhibitor) at a concentration of 10 $\mu \mathrm{g} / \mathrm{ml}$. Stimulated cells were incubated in $\mathrm{CO}_{2}$ incubator for $6 \mathrm{~h}$ stained with fluorochrome-conjugated antibody specific for the desired antigen. The analysed cells were fixed with CellFix and submitted to cytometric analyses using Becton Dickinson FACSCalibur. A minimum of 10,000 leukocytes were gated and analysed with CELL Quest software (Becton Dickinson). The results were presented as a percentage of cells with a specific response. The variable number of analysed patients is presented in the respective tables.

\section{Statistics}

Statistica/Win 5.0 software was used for all the calculations and statistical analyses. The data are expressed as mean \pm SEM. Statistical analysis regarding the differences between means was carried out by the Student's $t$-test, the paired Student $t$-test or the Fisher exact test. The differences in cytokine production were analysed using both Student's paired $t$-test and Fisher's exact test. $p \leq 0.05$ was considered to represent a significant difference between analysed data.

\section{Results}

The cytokine evaluations were performed in randomly chosen patients who readily consented to repeat the examinations having shown considerable improvement after the treatment with GnRH-Analogous Goserelin. IFN- $\gamma$ production by isolated lymphocytes after T-cell mitogen PHA stimulation was diminished in women with endometriosis before the treatment. This production increased after the treatment but was lower as compared with the control group (Table 1). IL-4 production was significantly augmented after PHA stimulation of lymphocytes from women with endometriosis before the treatment. IL-4 production by lymphocytes derived from women with endometriosis after treatment with the GnRH-Analogous Gorserelin was nearly normal after PHA stimulation and decreased after Concanavalin A (ConA) (Sigma, Saint Louis, MO, USA) stimulation as compared with the appropriate control group. Pro-

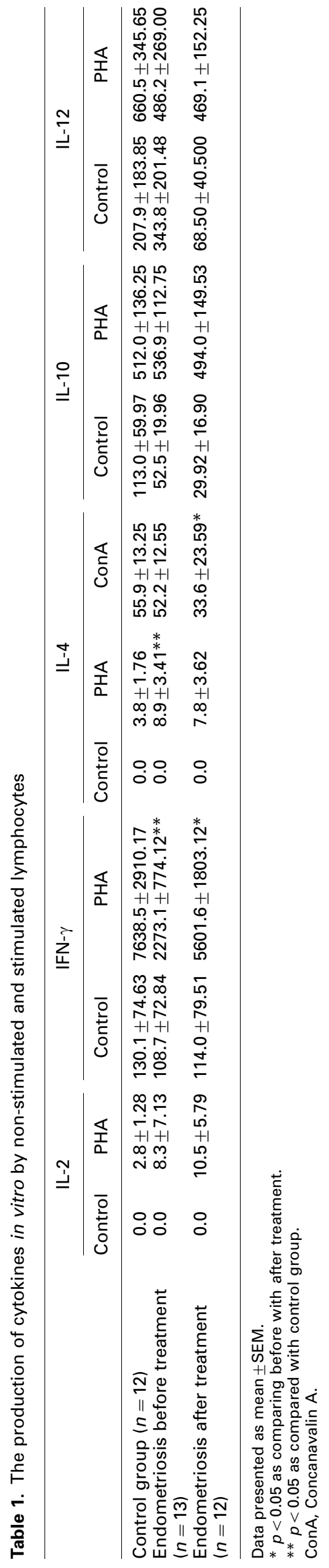

Mediators of Inflammation · Vol 12 2003 
duction of IL-2, IL-10 and IL-12 by PHA-stimulated lymphocytes did not differ statistically in all examined groups because of a relatively large scatter. The ICS method provides quantitative, functional and phenotypic assessment of $\mathrm{T}$ cells responsible for cytokine production. We originally proved the increase in $\mathrm{T}$ cells with IL- 6 and TNF- $\alpha$ deposits and the decrease of those with IFN- $\gamma$ deposits in the course of endometriosis disease. Both methods used for cytokine production analysis pointed out that $\mathrm{T}$ cells play a critical role in the control of inflammation and endometriosis development. The presented results have directly proved that the cell stimulators, both immune and bacterial in origin, may be responsible for the autocrine induction of proinflammatory TNF- $\alpha$ production and growth factors release by $\mathrm{T}$ cells. The T-cell number with IFN- $\gamma$, IL-4, IL-6 and TNF- $\alpha$ intracellular deposits are presented in Table 2. Lymphocytes from patients with endometriosis produced significantly more IL- 6 and TNF- $\alpha$; surprisingly there were no differences in IL- 4 and IFN- $\gamma$ production evaluated using the ICS method.

These results originally prove that analysed inflammatory cytokines may be produced by $\mathrm{T}$ lymphocytes. Peritoneal or peripheral blood macrophages stimulated by lipopolysaccharide, which are investigated in the majority of presented papers, ${ }^{2-4}$ are involved in the pathogenesis of endometriosis, but activated $\mathrm{T}$ cells undoubtedly accompany macrophages. Examples of cytometric analyses of intracellular cytokine deposit are presented in Figs. 1 and 2. The data presented prove a critical role of T-cell subset distribution in peripheral blood, peritoneal fluid and endometrial tissues, which are shown in Table 3. We have compared the T-cell subset distribution and some cytokine levels with regards to AFS stages and scores but no differences were observed. The significant increase in CD4:CD8 ratio was noted in peripheral blood of women at all stages of endometriosis, and it was independent of disease progression and varied form 1.28 in the control group to 2.0 (Fig. 3). The decrease in CD3/CD8, CD19 and NK cell percentages was observed in peripheral blood of women with endometriosis (Fig. 3). The diminished percentages in $\mathrm{CD} 3, \mathrm{CD} 3 / \mathrm{CD} 8$ cells and CD4:CD8 ratio directly proved the autocrine and regulatory function of $\mathrm{T}$ cells in endometriotic tissues. No correlation was found between cytokine production, lymphocyte subset distribution and the clinical
CONTROL
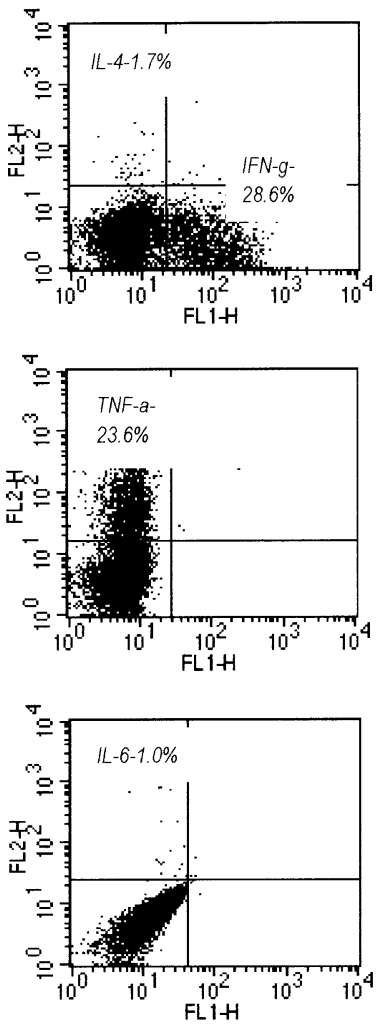

ENDOMETRIOSIS
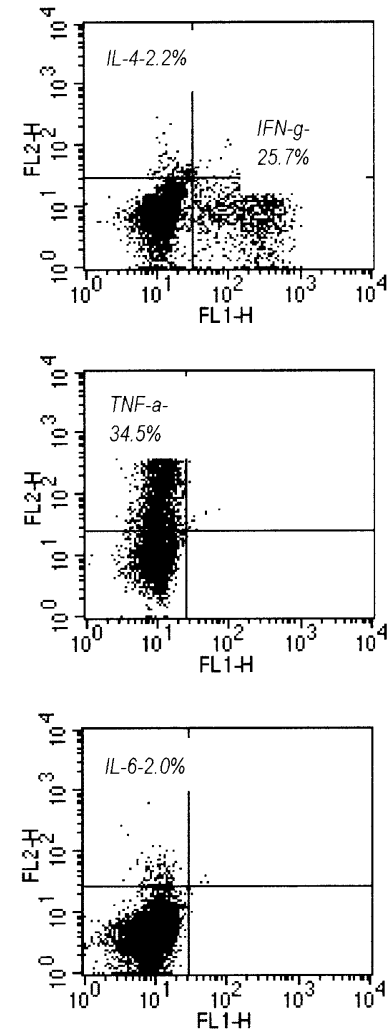

FIG. 1. Representative dot-plots obtained from analysis of intracellular deposits of IFN- $\gamma$, IL-4, TNF- $\alpha$ and IL-6 in stimulated peripheral blood cells of healthy women (control) and women with endometriosis. The decreased expression of IFN- $\gamma$ and increased expression of TNF- $\alpha$ was observed in peripheral blood cells of women with endometriosis.

stage of the disease (not shown) or the clinical status of the patient.

\section{Discussion}

Endometrial tissues and tissues desquamated during the menstrual bleeding can implant and develop ectopic lesions in $2-5 \%$ of women. ${ }^{1,2}$ Deficient local natural immunity against retrograde endometrium inoculation, an imbalance in cytokine production, defective T-cell IFN- $\gamma$ production, and a diminished number of NK cells may be the reasons for local proliferation of ectopic endometrial tissue. ${ }^{1,5}$

The peritoneal fluid from women with endometriosis contains mainly activated macrophages analysed by a majority of authors involved in the

Table 2. The peripheral blood T-cell percentages expressing intracellular deposits of IFN- $\gamma$, IL-4, IL-6 and TNF- $\alpha$

\begin{tabular}{lllll}
\hline Groups & \multicolumn{1}{c}{ IFN- $\gamma$} & IL-4 & IL-6 & TNF- $\alpha$ \\
\hline Control $(n=14)$ & $27.9 \pm 8.3$ & $1.69 \pm 0.84$ & $1.0 \pm 1.03$ & $25.1 \pm 7.43$ \\
Endometriosis $(n=14)$ & $25.7 \pm 12.0$ & $2.23 \pm 1.18$ & $2.0 \pm 1.90^{*}$ & $33.4 \pm 14.11^{*}$ \\
\hline
\end{tabular}

Data presented as mean \pm SD.

* $p \leq 0.05$ as compared with control group. 
BLOOD
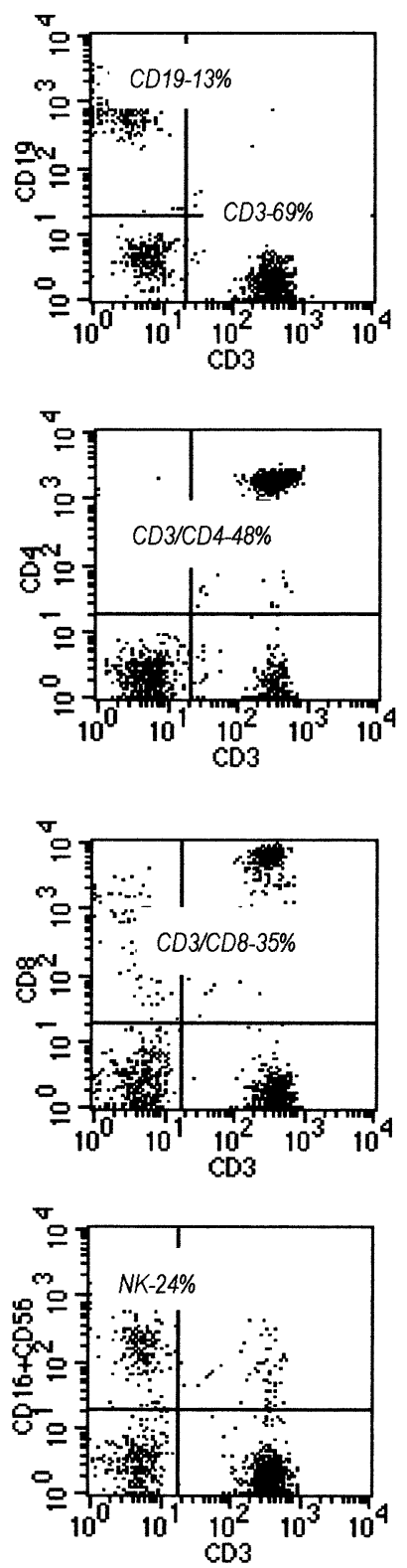

PERITONEAL FLUID
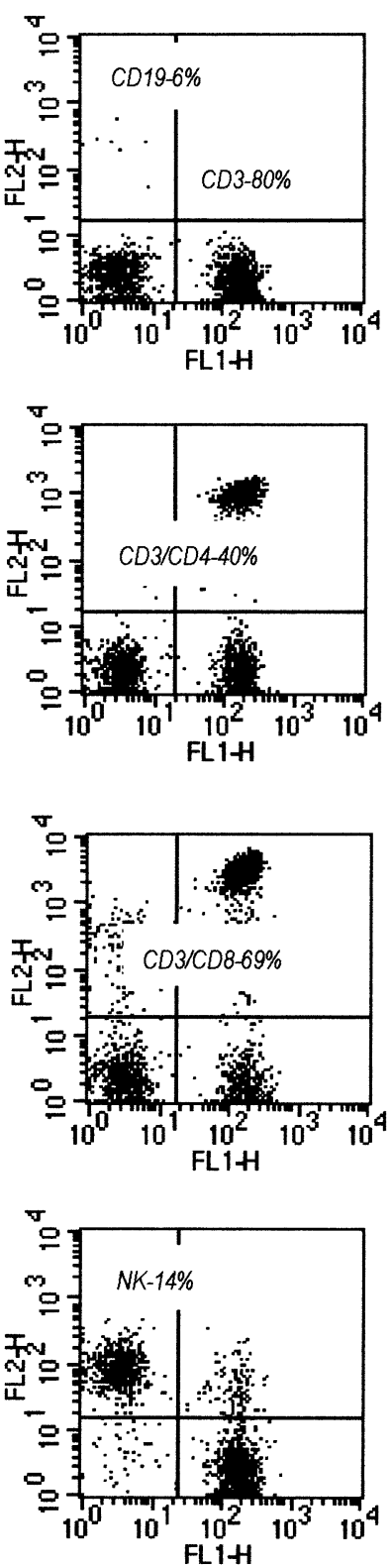

ENDOMETRIOTIC TISSUES
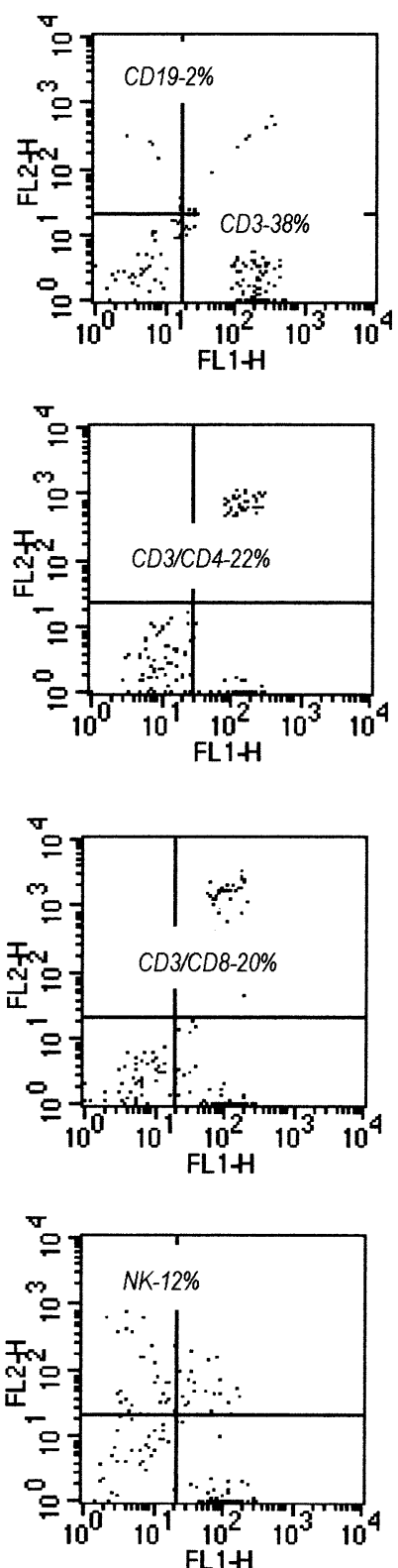

FIG. 2. Distribution of CD19, CD3, CD4, CD8 and NK cells among peripheral blood, peritoneal fluid and endometric tissue of women with endometriosis. A representative example of one patient investigation is presented. The diminished number of NK cells in peritoneal fluid and endometric tissue was noted.

Table 3. Distribution of lymphocyte subpopulations in women with endometriosis

\begin{tabular}{lcccccc}
\hline Lymphocyte source & $\mathrm{CD} 3$ & $\mathrm{CD} 3 / \mathrm{CD} 4$ & $\mathrm{CD} 3 / \mathrm{CD} 8$ & $\mathrm{CD} 4: \mathrm{CD} 8$ & $\mathrm{CD} 19$ & $\mathrm{NK}$ \\
\hline $\begin{array}{l}\text { Peripheral blood of healthy women } \\
(n=30)\end{array}$ & $69.3 \pm 6.40$ & $45.8 \pm 7.30$ & $34.2 \pm 5.71$ & $1.38 \pm 0.350$ & $12.9 \pm 3.84$ & $18.0 \pm 6.00$ \\
$\begin{array}{l}\text { Peripheral blood of women with en- } \\
\text { dometriosis }(n=60)\end{array}$ & $71.3 \pm 7.50$ & $45.1 \pm 8.19$ & $28.0 \pm 5.74^{*}$ & $1.81 \pm 0.701^{*}$ & $11.9 \pm 4.05^{*}$ & $16.5 \pm 5.84^{*}$ \\
$\begin{array}{l}\text { Peritoneal fluid from women with } \\
\text { endometriosis }(n=22)\end{array}$ & $72,6 \pm 12,48^{* *}$ & $23.1 \pm 8.47^{* *}$ & $49.9 \pm 11.65^{* *}$ & $0.50 \pm 0.290^{* *}$ & $2.6 \pm 2.97^{* *}$ & $14.3 \pm 8.41$ \\
Endometriotic tissues $(n=12)$ & $37.8 \pm 30.03^{\dagger}$ & $22.7 \pm 19.74$ & $21.6 \pm 16.62^{\dagger}$ & $1.08 \pm 0.339^{\dagger}$ & $2.4 \pm 2.21$ & $12.9 \pm 10.01$
\end{tabular}

Data presented as mean \pm SD.

* $p<0.05$ as compared with healthy women.

** $p<0.05$ as compared with peripheral blood of women with endometriosis

${ }^{\dagger} p<0.05$ as compared with peritoneal fluid of women with endometriosis. 

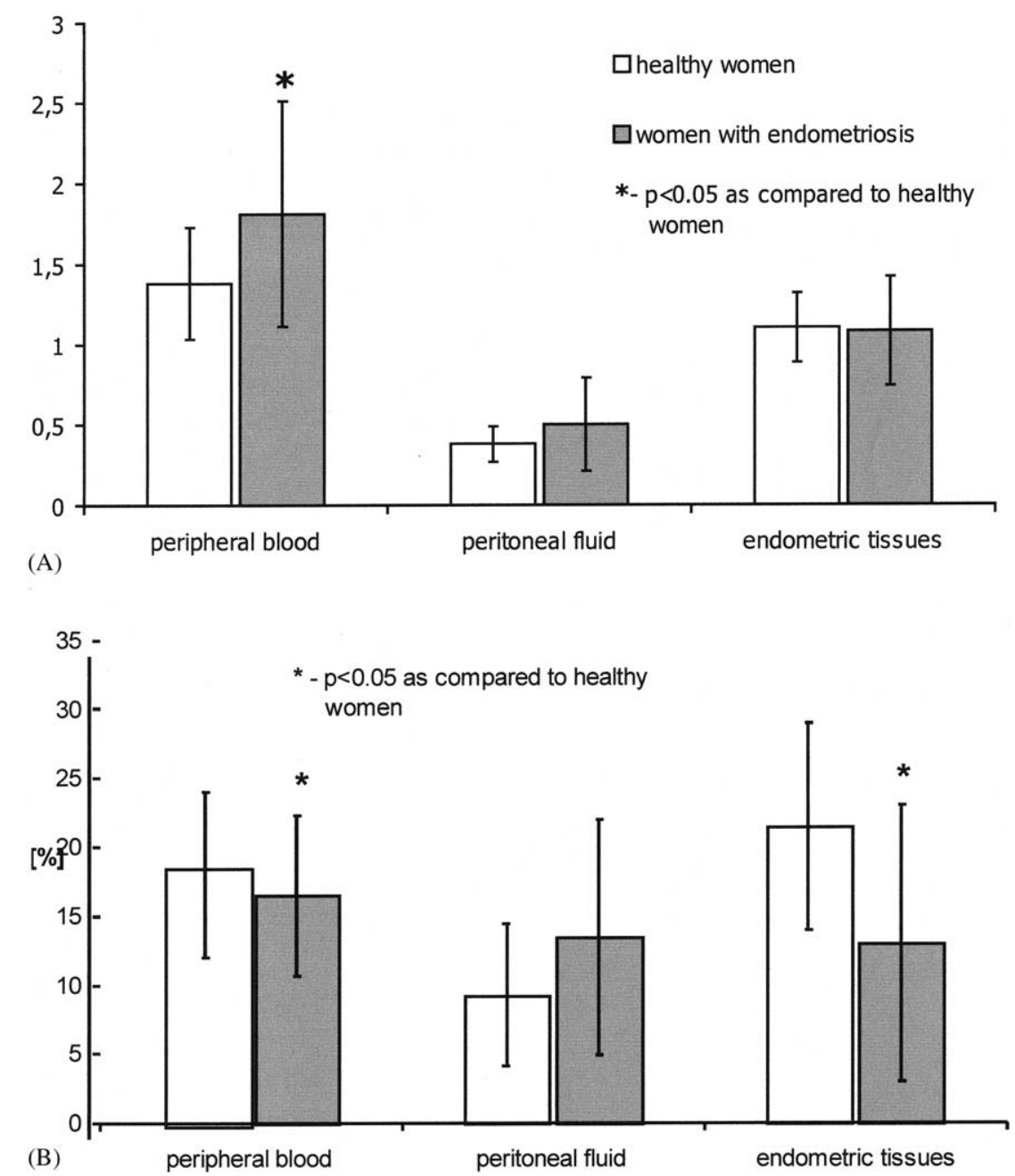

FIG. 3. Distribution of CD4:CD8 index (A) and NK cell percentages (B) in women with endometriosis (60) and in healthy volunteers (30). The number of performed investigations is presented in parentheses. Mean \pm standard deviation.

problem. Secretary products of these cells activate fibroblasts present in the peritoneal wall in an autocrine way and lead to a rapid production of interleukins (IL-6, IL-8). ${ }^{6}$ Fibroblast can also regulate the Th1-Th2 polarisation in the inflamed tissue.,

We have observed diminished IFN- $\gamma$ production by peripheral blood $\mathrm{T}$ lymphocytes stimulated with PHA, which may account for ectopic proliferation of endometrial cells. Diminution in IFN production in women with endometriosis, also confirmed by other authors on the macrophage, ${ }^{8}$ may be responsible for diminished NK cell activity, ${ }^{9}$ T-cell proliferation ${ }^{10}$ and diminished number of NK cells both in peripheral blood, peritoneal fluid and ectopic endometriotic tissues. ${ }^{11}$ Surprisingly, the intracellular level of IFN- $\gamma$ was not diminished in peripheral blood lymphocytes, contrary to the diminished PHA-induced IFN- $\gamma$ production by T cells, which was nearly normalised after the treatment of endometriosis.

The increase in the intracellular level of TNF- $\alpha$ and enhanced capacity of IFN- $\gamma$ production may be synergistically responsible for endometrial cell stimu- lation to produce growth mediator. ${ }^{3}$ The increased IL4 secretion by lymphocytes from patients with endometriosis was noted after PHA stimulation only. Hsu et al. ${ }^{12}$ also observed enhanced IL-4 expression in patients with endometriosis. IL-4 inhibits the IL-2-dependent activation of $\mathrm{T}$ cells and generation of lymphokine-activated killer cells, as well as simultaneously opposing the effects of IFN- $\gamma$ on human monocyte apoptosis. ${ }^{13}$ In patients with endometriosis, lymphocyte-mediated cytotoxicity plays a major role in the clearance of ectopic endometrial cells. ${ }^{14}$ The diminished activity of cytotoxic cells induced by enhanced production of IL- 4 combined with insufficient IFN- $\gamma$ production may result in the pathological growth of endometrial cells in the peritoneal cavity and the development of endometriosis. The increased number of cells with proinflammatory cytokine deposits (IL- 6 and TNF- $\alpha$ ) suggests that endometriosis may be a chronic inflammatory disease like rheumatoid arthritis, but the rheumatoid disease is characterised by a deficit in IL-4 production. ${ }^{15}$ Thus, the elevated secretion of IL-4 
in patients with endometriosis may suggest the existence of autoregulatory reactions toward prevention of further adhesion and disease progress.

IFN- $\gamma$ triggers the adaptive T-cell-mediated immunity, activation of cytotoxic $\mathrm{T}$ cells and constitutes a critical link between innate and acquired immunity. ${ }^{16}$ The normalisation of IFN- $\gamma$ production after treatment of endometriosis with GnRH-Analogous Goserelin proves the direct stimulatory effect on $\mathrm{T}$ lymphocytes resulting from the depression of estradiol, ${ }^{17}$ and supports the hypothesis of the crucial role of this cytokine in the development of endometriosis. Natural cytotoxic cells in women with endometriosis express killer inhibitory receptors that recognise major histocompatibility complex class I antigens on target cells and signal inhibition of cytotoxicity against the K562 target cell line. ${ }^{18}$

IFN- $\gamma$ exerts an autocrine stimulatory effect on lymphocytes and granulocytes, and is responsible for granulocyte priming observed during pregnancy. ${ }^{19}$ Diminished IFN- $\gamma$ production by lymphocytes observed in women with endometriosis may be crucial for the disease exacerbation as it was observed, for example in the course of rheumatoid arthritis in pregnant women expressing low IFN- $\gamma$ levels. ${ }^{19}$

Lymphocyte subpopulations in women with endometriosis have been analysed by many authors for the past 20 years and different results were obtained both in peripheral blood, peritoneal fluid and in endometriotic cells. ${ }^{20,21}$ The increase in CD 4 helper cell number and the decrease in CD8 suppressors in about $50 \%$ of the patients studied was observed in our study; others did not observe any significant changes. We performed the investigations both in peripheral blood, endometriotic tissues and peritoneal fluid in a relatively big group of patients at different stages of the disease. Such a complex study had not been carried out until now. Changes in the Tcell subpopulations, which were observed in women with endometriosis, did not correlate with cytokine production by the lymphocytes and the disease stage.

The obtained results provide evidence for the shift in the balance of PHA-activated Th1/Th2 cytokine secretion toward the Th2 arm, which resulted in diminished IFN- $\gamma$ production and increased IL-4 production. It was proved that low level of IFN- $\gamma$ is responsible for tumor cell implantation and natural surveillance against cancer. ${ }^{22}$ The same processes may decide on the retrograde endometriotic cell implantation and endometriosis development. The significant increase of lymphocytes with intracellular deposits of IL- 6 and TNF- $\alpha$ may suggest the presence of immune reactions as we observed in prediabetics. ${ }^{23}$ The non-significantly diminished production of IL-10 is contrary to that observed in autoimmune prediabetics both by lymphocytes and neutrophils. ${ }^{24}$ The diminished IL-10 production may favor the autoreactive cell function, neutrophil apoptosis and inflammatory reactions. ${ }^{24}$ With regards to a potential role for cytokine-independent mechanisms for regulatory T-cell function, ${ }^{2}$ we provide the new data concerning the role of regulatory $\mathrm{T}$ cells with the increased number of CD4 and T-cell-expressing intracellular deposits of IL- 6 and TNF- $\gamma$ in the pathogenesis of endometriosis. Secreted TNF- $\alpha$ may be directly responsible for stimulation of ectopic endometrial cell proliferation and local inflammation. The presented paper points out the crucial role of regulatory $\mathrm{T}$ cells in the pathogenesis of endometriosis.

ACKNOWLEDGEMENT. This study was supported by the Polish Scientific Committee (KBN 4 PO5E 11 215).

\section{References}

1. Hornung D, Klingel K, Dohrn K, Kandolf R, Wallwiener D, Taylor RN. Regulated on activation, normal T-cell-expressed and secreted mRNA expression in normal endometrium and endometriotic implants: assessment of autocrine/paracrine regulation by in situ hybridization. $A m J$ Pathol 2001; 158: 1949-1954.

2. Chatenoud L, Salomon B, Bluestone JA. Suppressor T cells-they're back and critical for regulation of autoimmunity! Immunol Rev 2001; 182: $149-163$.

3. Arima K, Nasu K, Narahara H, Fujisawa K, Matsui N, Miyakawa I. Effect of lipopolysaccharide and cytokines on production of Rantes by cultured human endometrial stromal cells. Mol Hum Reprod 2000; 6: 246-251.

4. Zeyneloglu HB, Senturk LM, Seli E, Bahtiyar OM, Olive DL, Arici A. The peritoneal fluid levels of interleukin-12 in women with endometriosis. Am J Reprod Immunol 1998; 39: 152-156.

5. Hoeger KM, Guzick DS. An update on the classification of endometriosis. Clin Obstet Gynecol 1999; 42: 611-619.

6. Buckley CD, Pilling D, Lord Janet M, Akbar Arne N, Scheel-Toellner D, Salmon M. Fibroblasts regulate the switch from acute resolving to chronic persistent inflammation. Trend Immunol 2001; 22: 199-204.

7. Hogaboam CM, Bone-Larson CL, Lipinski S, Lukacs NW, Chensue SW, Strieter RM, Kunkel SL. Differential monocyte chemoattractant protein-1 and chemokine receptor 2 expression by murine lung fibroblasts derived from Th1-and Th2-type pulmonary granuloma models. $J$ Immunol 1999; 163: 2193-2201.

8. Keenan A, Chen TT, Chadwell NL, Torry DS, Caudle MR. Interferongamma (IFN- $\gamma$ ) and interleukin-6 (IL-6) in peritoneal fluid and macrophage-conditioned media of women with endometriosis. Amer J Reprod Immunol 1994; 32: 180-183.

9. Ho HN, Wu MY, Yang YS. Peritoneal cellular immunity and endometriosis. Amer J Reprod Immunol 1997; 38: 400-412.

10. Ho HN, Wu MY, Chao KH, et al. Decrease in interferon gamma production and impairment of T-lymphocyte proliferation in peritoneal fluid of women with endometriosis. Am J Obstet Gynecol 1996; 175: $1236-1241$

11. Oosterlynck DJ, Lacquet FA, Mear WM, Koninckx PR. Lymphokineactivated killer activity in women with endometriosis. Gynecol Obstet Invest 1994; 37: 185-190.

12. Hsu CC, Yang BC, Wu MH, Huang KE. Enhanced interleukin-4 expression in patients with endometriosis. Fertil Steril 1997; 67: 1059-1064.

13. Mangan DF, Robertson B, Wahl SM. IL-4 enhances programmed cell death (apoptosis) in stimulated human monocytes. I Immunol 1992; 148: $1812-1816$

14. Vigano P, Vercellini P, Di Blasio AM, Colombo A, Candiani GB, Vignali M. Deficient antiendometrium lymphocyte-mediated cytotoxicity in patients with endometriosis. Fertil Steril 1991; 56: 894-899.

15. Miossec P, Banchereau J. Interleukin 4: a potential antitumor and antiinflammatory agent. In: Oppenheim J, Rossio JL, Gearing AJH, eds. Clinical Applications of Cytokines, Oxford: Oxford University Press, 1993: $171-176$.

16. Kadowaki N, Antonenko S, Lau JY, Liu YJ. Natural interferon alpha/betaproducing cells link innate and adaptive immunity. J Exp Med 2000; 192: $219-226$.

17. Hsu CC, Lin YS, Wang St, Huang KE. Immunomodulation in woman with endometriosis receiving GnRH agonist. Obstet Gynecol 1997; 89: 993998 . 
18. Wu MY, Yang JH, Chao KH, Hwang JL, Yang YS, Ho HN. Increase in the expression of killer cell inhibitory receptors on peritoneal natural killer cells in women with endometriosis. Fertil Steril 2000; 74: 187-1191.

19. Tchorzewski H, Krasomski G, Biesiada L, Glowacka E, Banasik M, Lewkowicz P. IL-12, IL-6 and IFN- $\gamma$ production by lymphocytes of pregnant women with rheumatoid arthritis remission during pregnancy. Mediat Inflamm 2000; 9: 289-293.

20. Gleicher N, Dmowski WP, Siegel I. Lymphocyte subsets in endometriosis. Obstet Gynecol 1984; 63: 463-466.

21. Klentzeris LD, Bulmer JN, Liu DT, Morrison L. Endometrial leukocyte subpopulations in women with endometriosis. Eur J Obstet Gynecol Reprod Biol 1995; 63: 41-47.

22. Belardelli F, Ferrantini M. Cytokines as a link between innate and adaptive antitumor immunity. Trends Immunol 2002; 23: 201-208.
23. Tchórzewski H, Glowacka E, Banasik M, Lewkowicz P, Szalapska Zawodniak M. Activated T lymphocytes from patiens with high risk of type I diabetes mellitus have different ability to produce interferon- $\gamma$, interleukin-6 and interleukin 10 and undergo anti-CD95 induced apoptosis after insulin stimulation. Immunol Lett 2001; 75: 225-234.

24. Glowacka E, Banasik M, Lewkowicz P, Tchórzewski H. The effect of LPS on neutrophils from patients with high risk of type I diabetes mellitus in relation to IL-8, IL-10 and IL-12 production and apoptosis in vitro. Scand J Immunol 2002; 55: 210-217.

Received 6 February 2003

Accepted 17 March 2003 


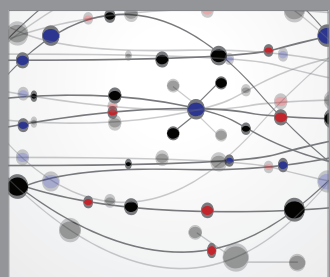

The Scientific World Journal
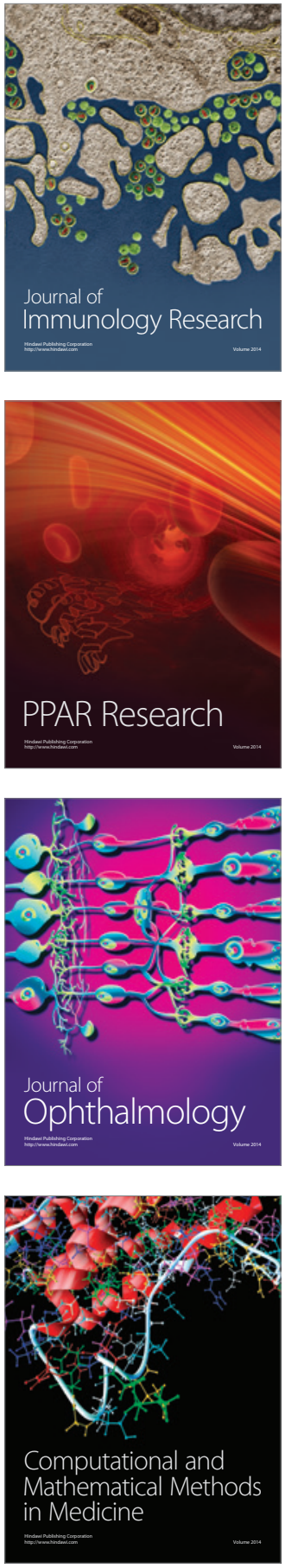

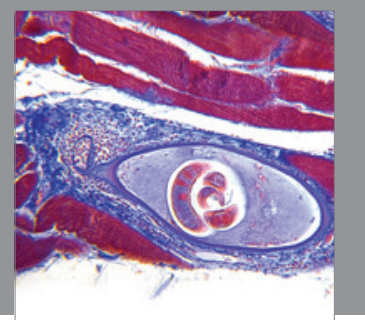

Gastroenterology

Research and Practice
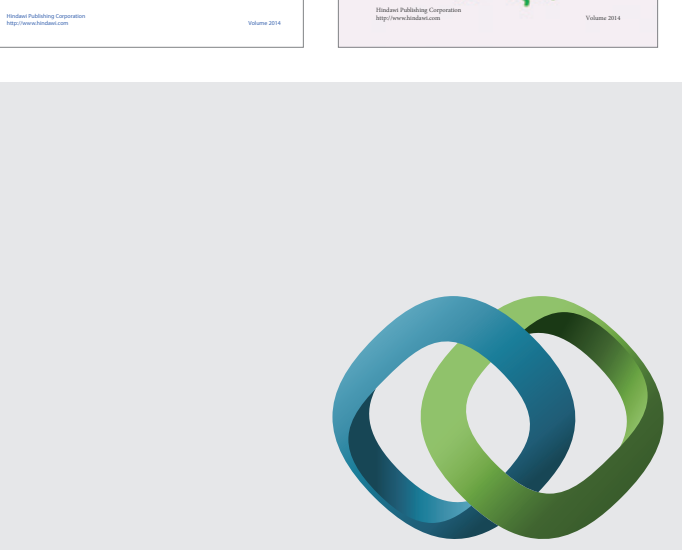

\section{Hindawi}

Submit your manuscripts at

http://www.hindawi.com
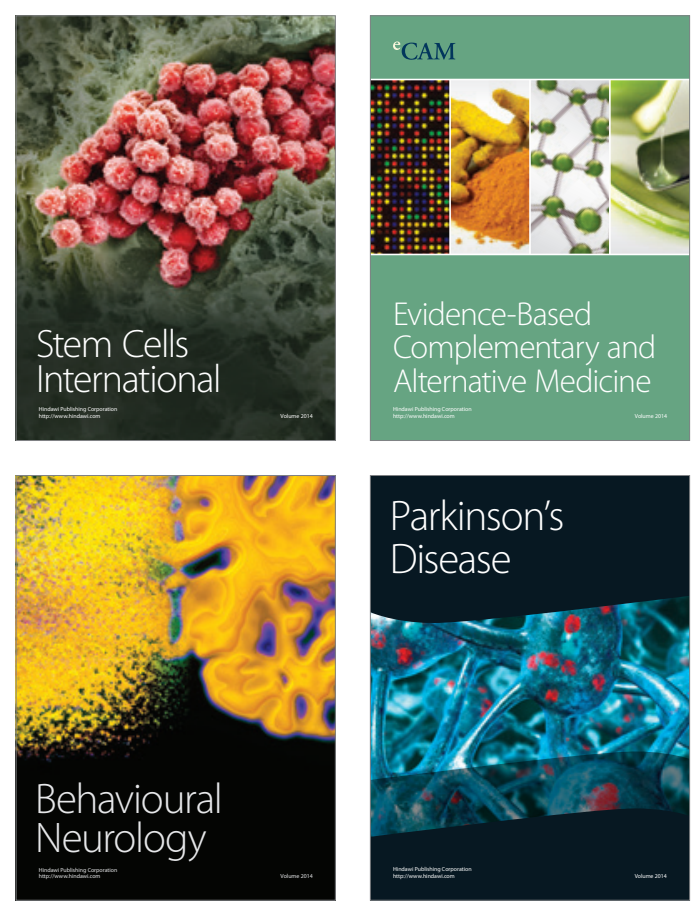

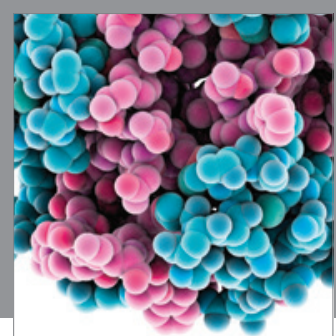

Journal of
Diabetes Research

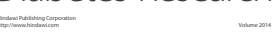

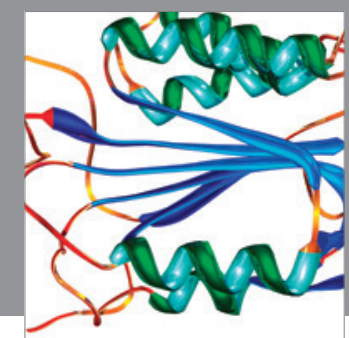

Disease Markers
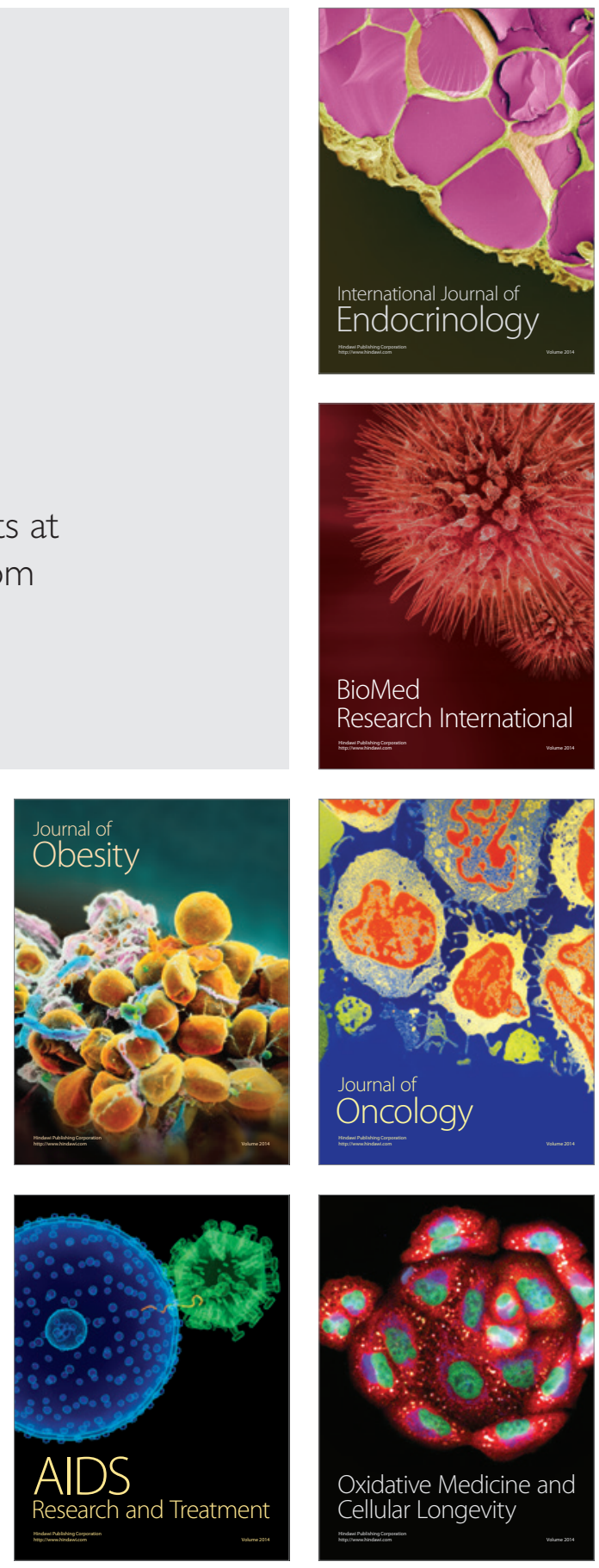